\title{
Job Satisfaction, Organizational Commitment, and Organizational Citizenship Behaviour in State-owned Banking
}

\author{
Arif Partono Prasetio, ${ }^{1, *}$ Tjutju Yuniarsih ${ }^{2}$, Eeng Ahman ${ }^{2}$ \\ ${ }^{1}$ School of Economic \& Business, Telkom University, Indonesia \\ ${ }^{2}$ Faculty of Economic and Business Education, Indonesia University of Education, Indonesia
}

Copyright $\bigcirc 2017$ by authors, all rights reserved. Authors agree that this article remains permanently open access under the terms of the Creative Commons Attribution License 4.0 International License

\begin{abstract}
Organization need to develop its human resources in a way that can build the high level of organizational citizenship behaviour (OCB). Job satisfaction and organizational commitment can became an important factor which affecting OCB. The aim of this study is to identify the mediating role of organizational commitment in the relationship between job satisfaction and OCB. The samples were derived from a survey using 39 items questionnaire distributed to the 320 employees of a state-owned banking in Bandung, Indonesia. All respondents hold positions in marketing and small business market. The bootstrap confidence interval used to measure the mediation. The result revealed that there was a direct and indirect effect in the relation between job satisfaction and OCB. Since the interval did not contain zero in the equation, then the research found these relations was mediated by organizational commitment. Organizational commitment indeed contributes as mediator in the effect of job satisfaction on OCB.
\end{abstract}

Keywords Organizational Commitment, Job Satisfaction, Organizational Citizenship Behavior

\section{Introduction}

The organization's performance considered an important aspect. In order to achieve their goals, the organization needs to serve better products or services to their customers. In Indonesia's banking industry, the competition to gain the market is intense. The company needs their human resources as their new strategy to gain competitive advantage. They want their employees to perform well at all times in their job. They also need employees whose willing to contribute more and perform extra-role behaviors to help the organization become more effective. The extra-role behaviors also known as organizational citizenship behavior (OCB) as defined by
Organ \& Lingl [1] as an individual contribution that neither contractually rewarded nor enforceable by supervision or job requirements. In this case, employee did not have to do it, but they in fact did it. The OCB, are not compulsory or describe clearly in job descriptions, they are also not rewarded nor punished [2]. Previous research has indicated that OCBs can influence organizational performance [3] \& [4]. The benefits of the OCB in improving organizational performance also mention by Podsakoff et al [5]. Meanwhile, Becton et al [6] argued that the organization should encourage their employees to perform OCB for it is crucial for their success.

The purpose of this study is to investigate the effect of job satisfaction on OCB through the mediation of organizational commitment (OC) in a state-owned bank. Recently, OCB has gain many attention from various researchers such as; Dalal [7], Kuehn \& Al-Bushaidi [8], Lin \& Chang [9], LePine et al [10], Ngadiman [11], Qamar [12], Shafazawana et al [13], and Schappe [14]. These researchers came from various different cultures like Asia and western. It proved that OCB had studied in many countries as well. Factors which can affect OCB already identified such as job satisfaction, leadership, organizational commitment, and fairness [10].

The banking industries faced difficult times and new challenges as the governments tried to lower the interest rate. They need to gain more market, either by snatching their competitor's market or opening new one. This state-owned bank currently ranked in fourth place for their productivity. Since they enjoy the largest assets, the current position did not please the management. Moreover they own the widest network in Indonesia and also the largest employees. The management felt they should do better. Although the problems can be caused by many things, the management wanted to know was there any problems with the human resources. Based on the initial observations, we turned to the job attitude aspect of satisfaction and organizational commitment.

We believed that satisfaction towards the job and the 
employee's organizational commitment can enhance the OCB. This notion based on the previous research from Kasemsap [15] who found that job satisfaction and organizational commitment had moderate positive effect on OCB. Previous researches from Ackfeldt and Coote [16], Bowling, Wang and Li [17], and MacKenzie et al [18] gave affirmation that job satisfaction and organizational commitment as the key job attitude can support and predict OCB.

The relationships between job satisfaction, organizational commitment, and OCB have been studied numerous times in various organizations. Yet the study in Indonesia banking industry is still limited. While the main purpose is to identify the relationship of job satisfaction and organizational commitment, this study also addressed to develop OCB analysis in Indonesia. The fact that this study was conducted in the Indonesian culture will enhance the OCB literatures.

\section{Literature Review}

Many of job attitude aspects can be traced from the social exchange, conservation of resources (COR), and affective events theory. The interaction between employee, supervisor, and organization consists of the exchange process. Homans [19] argued that the interaction between person include exchange of goods, whether material or non-materials. While Emerson [20] confirmed that social exchange as an action that contingent on rewarding reactions from others. When one person felt gaining benefit from what they do, they will repeat the action. The more employees feel that they satisfied with their job the more likely they are committed and perform better. They are even willing to do more than they asked because they feel like doing it. It can be said, when organization showed a positive action, such action can drive employees to reciprocate in mutual ways [21].

The theory of COR from Hobfolll [22] viewed that people strive to collect, protect, and develop resources. The loss of potential loss of the resources considered as threatening. The application of COR theory in work attitudes and performance are very clear. Individual needs to gain resources (money, self-esteem) and in the meantime they sacrifice the other resources (time, energy). And usually both cannot meet the ideal conditions where they can achieve balance. Employees should juggle between the effort to gain resources and the effort to protect the loss of resources. COR can explain why employees become satisfied and more committed and willing to do more.

To understand the model, we continue this literature review by providing basic explanation about job satisfaction, organizational commitment, and OCB. We use the definition of job satisfaction from Uhl-Bien et al [23] which explained as an attitude that reflect the individual positive and negative feeling towards their job. It is clear that the definition reflect what employees perceive about their job. As for the organizational commitment, hold on to definition from
Schermerhorn et al [24] which defined commitment as the degree of loyalty from individual toward the organization. The organizational commitment is a continuous employee's attitude towards the organization. Schermerhorn et al [24] also emphasized that highly committed employees will likely identify themselves with the organization. Robbins \& Judge [25] explained the OCB as the discretionary behaviour which are not part of their formal job description. The explanation clearly shows the relation between OCB and the employee's internal motivation.

\subsection{Job Satisfaction and OCB}

The satisfied employees will show high OCB. Organ argued that satisfied employees have higher OCB because they want to reciprocate to the organization whose already treat them well [26]. Wagner \& Hollenbeck [27] strengthen this notion. Numerous literatures regarding the relation of job satisfaction and OCB easily obtained. Research in health care sector by Chahal \& Mehta [28] showed there was positive and significant effect from job satisfaction on OCB. While study from Holland with various industries background by Koning \& van Kleef [29] revealed the same result. When the satisfaction high, then OCB increased. Other scholars such as Foote \& Tang [30], Intaraprasong [31], Mohammad et al [32], Pavalache-Ilie [33], Qamar [12], Swaminathan \& Jawahar [34], Talachi et al [35] also found positive and significant relation between job satisfaction and OCB. That is the individual who satisfied with the job displayed high OCB. Sesen \& Basim [2] and Zeinabadi [36] found the relations which mediated by organizational commitment. Following the previous founding, the job satisfaction will have a positive relation with employee's OCB (Hypothesis 1).

\subsection{Organizational commitment on OCB}

The higher the organizational commitment will drive employee OCB. This argument supported by previous researches from Kasemsap [15] who conduct the survey in Thailand and Liu \& Cohen [37] using public organization participant in Northern China. Study with Asian and African culture background from Wang [38] in Japan, Noor [39] in Pakistan, Asiedu et al [40] in Ghana, Ibrahim \& Aslinda [41] in Indonesia, and Bakhshi et al [42] in India were among the researchers who had the same argument about the positive and significance relation between these variables. Although these researches use different viewpoint (some directly related the organizational commitment, and some use the detail dimension; affective, cognitive, and normative), the result show the same pattern.

Meanwhile other researchers from western culture such as Morin et al [43], Devece et al [44], and Lavelle et al [45] showed that in Spain, Canada, and United States also the same result which is there is positive and significant relation between organizational commitment and OCB. Based on the previous researches concerning the relation between 
variables, we determine the second hypothesis for this research that there is positive and significant effect between organizational commitments on OCB (Hypothesis 2).

\subsection{Job satisfaction and Organizational Commitment}

Job satisfaction has long been known to have an influence on organizational commitment. Wagner \& Hollenbeck [27] argued that employee's dissatisfaction contribute to lowering the commitment. To strengthen the notion, we present previous research which discuss satisfaction and commitmen. Markovits et al [46] found the positive relation between satisfaction and commitment on in a research using Greeks as participants. The same result also found in the literatures from Azeem [47], Azeem and Akhtar [48], Irshad \& Naz [49], Gunlu et al [50], Sejjaaka \& Kaawaase [51], Veličković et al [52]. These researches use participants from Oman, India, Pakistan, Turkey, Uganda, and Serbia. Based on various literatures from different culture, the model suggests that job satisfaction is strong predictors for organizational commitment, where the dimensions of job satisfaction have slightly different significant effect on organizational commitment. If employees happy they will show higher commitment to their organization. This notion leads us to set the third hypothesis that there is a positive and significant relation between job satisfaction and organizational commitment (Hypothesis 3).

Based on the relation between each variable, we then organize a simple research model and the last hypothesis that job satisfaction directly and indirectly through mediation of organizational commitment will affect OCB (Hypothesis 4). The model derived from the individual relation between variables.

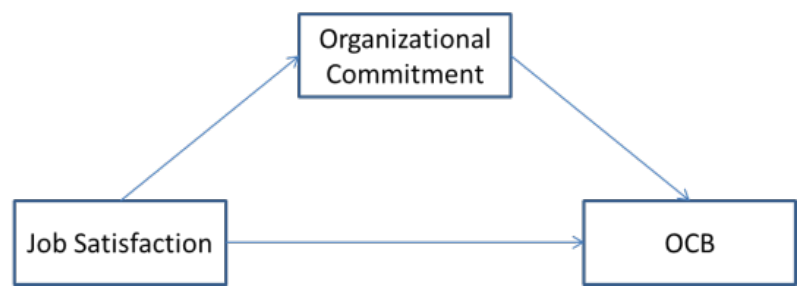

Figure 1. Mediation Model

\section{Methodology}

\subsection{Participants and Measurement}

The survey was conducted between August 2015 and February 2016. We used 320 employees of a state-owned bank in Marketing and Small Business Department across Bandung Area which includes Tasikmalaya, Ciamis, Kuningan, Sumedang, Cirebon, Garut, Indramayu, Bandung, West Bandung. A self-administered questionnaire was used to collect data for this study. 15 items for job satisfaction develop based Spector's global job satisfaction measure [53]. By using five sub-scales; satisfaction with supervisor, income, career development, nature of work, and co-worker relations, we asked the participants to give their response using 5-point scale ranging from 1 (Strongly Disagree) to 5 (Strongly Agree). The Cronbach's Alpha for all 15 items was .91. Regarding the items for organizational commitment we develop 9 items using Meyer \& Allen concept [54], 5-point scale also used, range from 1 (Strongly Disagree) to 5 (Strongly Agree). Higher values indicated more commitment and the Cronbach's Alpha for the items was .74 .

Finally, the 15 items for OCB administered using Organ 5 sub-scale [55] and measured using five sub-scales; altruism, courtesy, conscientiousness, sportsmanship, and civic virtue. Once again, five-point Likert scale which ranged from 1 (Strongly Disagree) to 5 (Strongly Agree) was used. The Cronbach's Alpha for these items was .92.

\subsection{Procedures}

We recruited the participants with the permission of the bank management. We distributed the questionnaire throughout the 30 branches in Bandung Area. Data were collected by means of paper and pencil surveys given to the employees who were on duty on the day that we conduct the survey. The anonimity was guaranteed. We distributed 400 questionnaires and got valid response from 320 participants.

In order to assess the relationship between job satisfaction, commitment and organizational citizenship behaviour, Pearson's correlation and regression analyses were carried out. For determining whether direct and indirect effect, we use the bootstrap confidence interval from Hayes [56]. According Hayes, if the range of bootstrapping confidence interval (from upper and lower level) value are all above or below zero then we can say there is a mediation. But, if one of the confidence level contain zero, that mean there are no mediation. The confidence level obtains through the use of SPSS program with the added macro program called Process from Hayes [56].

\section{Results}

As described above, we run macro program named Process using SPSS. We use 5.000 number of bootstrap with $95 \%$ level of confidence. The table 1 showed the relation between job satisfaction, organizational commitment, and OCB.

Table 1. The Correlation

\begin{tabular}{lcccccc}
\hline & \multicolumn{3}{c}{ Commitment } & \multicolumn{3}{c}{ OCB } \\
& Coeff & SE & p-value & Coeff & SE & p-value \\
\hline Job Satisfaction & 0.610 & 0.195 & 0.000 & 0.334 & 0.055 & 0.000 \\
Commitment & - & - & - & 0.142 & 0.470 & 0.000 \\
\cline { 2 - 6 } & \multicolumn{3}{c}{$\mathrm{R}$ Square $=0,270$} & \multicolumn{2}{c}{$\mathrm{R}$ Square $=0,220$} \\
& \multicolumn{2}{c}{$\mathrm{F}=117,399$} & \multicolumn{2}{c}{$\mathrm{F}=44,482$} \\
$\mathrm{p}=0,000$ & $\mathrm{p}=0,000$ \\
\hline
\end{tabular}

From the above table, it was clear that both job satisfaction and organizational commitment were affecting OCB, 
partially and simultaneously. This table resulting from process is somewhat different compare to the table resulting from SPSS only. Meanwhile, job satisfaction also can predict the organizational commitment. The result supports the first three hypotheses; Job satisfaction had positive and significant relation with OCB (0.334). The second hypothesis also accepted, organizational commitment had positive relation with OCB $(0.142)$. The third hypothesis also proved that job satisfaction and commitment had positive and significant relation $(0.610)$.

To answer the last hypothesis, we have to look the result showed in Table 2 which revealed that the Lower Level of Confidence Interval (LLCI) and Upper Level Confidence Interval (ULCI) contain no zero (0) value. This met the mediation criteria from Hayes. The variable said to function as mediation if there are no 0 value between LLCI and ULCI.

Table 2. Direct \& Indirect Effect

\begin{tabular}{lccrr}
\hline & Effect & $\mathrm{p}$ & LLCI & \multicolumn{1}{c}{ ULCI } \\
\hline Total & 0,420 & 0,000 & 0,327 & 0,514 \\
Direct effect & 0,334 & 0,000 & 0,225 & 0,442 \\
\hline & Effect & Boot SE & BootLLCI & BootULCI \\
\hline Indirect Effect & 0,087 & 0,030 & 0,030 & 0,149 \\
\hline
\end{tabular}

Base from Table 2, we accept the fourth hypothesis. Organizational Commitment mediated the relation between job satisfaction and OCB. The result also showed that when the commitment variable included in the equation, it reinforce the effect of job satisfaction. If only from job satisfaction the effect was 0.334 . But, when mediated by organizational commitment, it experienced a slight grow to 0.420. In this case, organization should focus on both variables in building the employee's OCB.

\section{Analysis}

Many scholars studied the effect of job satisfaction and organizational commitment on OCB by measuring the effect separately. This study measure the direct effect of job satisfaction on $\mathrm{OCB}$, and the indirect effect through the organizational commitment. We believed that the commitment will increase the effect. The idea was based on the premise that happy people will have more commitment. Then they perform better in their extra-role. The extra role reflect OCB where employees voluntarily help co-workers, share their resources, represent the organization, working extra hour without getting paid, actively seeking solutions for company's problems, and respect for others. This kind of behaviour believed to be important for organizations. Overall this study strengthens the notion brought from previous literatures.

The relation between job satisfaction and organizational commitment is found to be significant and in positive direction. Therefore this study supports study from Markovits et al [46], Azeem [47], Azeem and Akhtar [48], Irshad \& Naz [49], Gunlu et al [50], Sejjaaka \& Kaawaase
[51], and Veličković et al [52]. In Indonesia, especially in Banking industry, job satisfaction turn out still become a factor that affect the organizational commitment. Not only that, the satisfaction also can develop higher OCB. This is in line with previous studies from various cutures. Koning \& van Kleef [29], Foote \& Tang [30], Intaraprasong [31], Mohammad et al [32], Pavalache-Ilie [33], Qamar [12], Swaminathan \& Jawahar [34], and Talachi et al [35] support the positive relation between these two variables.

The organizational commitment also proved had significant and positive relation with OCB. This finding also in line with studies from eastern culture by Kasemsap in Thailand [15], Liu \& Cohen in China [37], Wang in Japan [38], Noor in Pakistan [39], Asiedu et al in Ghana [40], and Bakhshi et al in India [42]. Literatures from western culture support the same notion, Morin et al [43], Devece et al [44], and Lavelle et al [45]. Since the findings also revealed that organizational commitment mediated the relation between job satisfaction and OCB, then this study was also in line with Sesen \& Basim [2] and Zeinabadi [36] who found the same mediation.

Banking industry need employee who committed and well-performed. Bank XYZ as the biggest state-owned bank also had the same requirement for their employees. Especially they rely most on their employees as the spearhead for serving the customers. The competition in banking, especially in small business customer is hard and fast. Each company develops its own strategy to win the market. Bank XYZ basically had the unique advantage because they penetrate deep into the farthest remote area. To maintain this advantage, they need to have employees who willing to travel and work outside regular office hour. They have to pursue and served the customer in whatever they need and want.

Based on this condition, Bank XYZ need to know what they can do to enhance the level of OCB. We proposed that they should develop human resources policy which can develop job satisfaction and organizational commitment. Policy such as better work condition, flexible hour, supervisors who understand what they need, competitive salary, clear career advancement, and challenging job can provide the ground to build satisfaction. Knowing that the organization take good care of them, employee will reciprocate and show more committed behaviour. As time goes by, the feeling get stronger and will enhance the extra-role performance (OCB).

Based on the theory of social exchange, employees will display OCB as a form of their reward to the organization. They are doing so because they have support and help from the organization. It is possible that bank employees, like other employees, prefer to do voluntary activities for their organization. Employees who chose to displays OCB believes they has a greater chance to be rewarded. Organization should not underestimate the findings, since the reciprocity usually applied. Employees felt satisfied will gave more to the company, with expectation they will achieve more. Bank XYZ should put serious effort in 
maintaining the level of satisfaction and organizational commitment. They can develop the human resources practices which promote better work environment.

\section{Conclusions}

It is concluded that job satisfaction and organizational commitment have positive and significant effect on OCB. We did not study the dimensions of OCB in detailed, because the measurement of OCB using specific dimensions did not provide any clear advantages. The study supports the previous literatures findings; job satisfaction has positive relation with organizational commitment and OCB and organizational commitment has positive relation with OCB. This study also found that in this case, organizational commitment mediated the relation of job satisfaction and OCB. Organization who wants their employees develop higher OCB, should focus on the human resources policy which related to the raise the job satisfaction and organizational commitment. More satisfied and more committed employees tend to exhibit higher OCB. The study is conducted in most part of West Java Province only so the future study can widen the geographical coverage to include other province to increase the generalizability of the results. As we also are doing, using different participants from various industries could extend the benefit of this study. In the end, it is suggested that as there is significant relationship between the job satisfaction and organizational commitment with OCB; so the management of banking sector should produce atmosphere where employees feel satisfied with job and committed with the organization.

\section{Acknowledgments}

I would like to thanks RISTEKDIKTI for providing the funding. I also thank Prof Tjutju Yuniarsih, Prof Eeng Ahman, Prof Karen Korabik, and Prof Gloria Gonzales Morales who guided me throughout the writing process.

\section{REFERENCES}

[1] Organ, D.W., Lingl, A. (1995). Personality, Satisfaction, and Organizational Citizenship Behavior. The Journal of Social Psychology. 135:3, pp.339-350.

[2] Sesen, H., \& Basim, N.H. (2012). Impact of Satisfaction and Commitment on Teachers' Organizational Citizenship. Educational Psychology: An International Journal of Experimental Educational Psychology. Vol. 32, No. 4, pp.475-491.

[3] Rayner, J. Lawton, A., Williams, H.M. (2012). Organizational Citizenship Behavior and the Public Service Ethos: Whither the Organization? Journal of Business Ethics, 106, pp.117-130. DOI 10.1007/s10551-011-0991-x
[4] Kizilos, M.A., Cummings, C., Cummings, T.G. (2013). How High-Involvement Work Processes Increase Organization Performance: The Role of Organizational Citizenship Behavior. The Journal of Applied Behavioral Science Vol. 49, No.4, pp.413-436.

[5] Podsakoff, P. M., MacKenzie, S. B., Paine, J. B., Bachrach, D.G. (2000). Organizational citizenship behaviors: A critical review of the theoretical and empirical literature and suggestions for future research. Journal of Management, Vol. 26, No. 3, pp.513-563.

[6] Becton, J. B., Giles, W. F., Schraeder M. (2008). Evaluating and rewarding OCBs: Potential consequences of formally incorporating organizational citizenship behavior in performance appraisal and reward systems. Employee Relations, 30(5): pp.494-514.

[7] Dalal, R.S. (2005). A Meta-Analysis of the Relationship Between Organizational Citizenship Behavior and Counterproductive Work Behavior. Journal of Applied Psychology, Vol. 90, No. 6, pp.1241-1255.

[8] Kuehn, K.W., Al-Busaidi, Y. (2002). Citizenship Behavior in a Non-Western Context: An Examination of the Role of Satisfaction, Commitment, and Job Characteristics on Self-Reported OCB. International Journal of Commerce and Management, Vol. 12 No. 2 pp.107 - 125.

[9] Lin, C.T., Chang, C.S. (2015). Job Satisfaction of Nurses and Its Moderating Effects on the Relationship Between Organizational Commitment and Organizational Citizenship Behaviors. Research and Theory for Nursing Practice: An International Journal, Vol. 29, No. 3, pp.226-244. http://dx.doi.org/10.1891/1541-6577.29.3.226.

[10] LePine, J.A. Erex, A., Johnson, D.E. (2002). The Nature and Dimensionality of Organizational Citizenship Behavior: A Critical Review and Meta-Analysis. Journal of Applied Psychology,Vol. 87, No. 1, pp.52-65.

[11] Ngadiman. (2013). Influence of Work Satisfaction and Organizational Commitment to the Organizational Citizenship Behavior of Lecturers at Faculty of Teachers Training and Education, Sebelas Maret University, Surakarta. Educational Research International. Vol. 1, No. 3. Pp.54-63.

[12] Qamar, N. (2012). Job Satisfaction and Organizational Commitment as Antecedents of Organizational Citizenship Behavior (OCB). Interdisciplinary Journal of Contemporary Research in Business. Vol. 4 No. 7, pp.103-122.

[13] Shafazawana, M.T., Ying, C.Y., Zuliawati, M.S., Kavitha, S. (2016). Managing Job Attitudes: The Roles of Job Satisfaction and Organizational Commitment on Organizational Citizenship Behaviors. Procedia Economics and Finance, 35, pp.604-611.

[14] Schappe, S.P. (1998). The Influence of Job Satisfaction, Organizational Commitment, and Fairness Perceptions on Organizational Citizenship Behavior. The Journal of Psychology: Interdisciplinary and Applied. Vol 132, No. :3, pp.277-290.

[15] Kasemsap, K. (2012). Factors Affecting Organizational Citizenship Behaviorof Passenger Car Plant Employees in Thailand. Silpakorn University Journal of Social Sciences, Humanities, and Arts. Vol.12 (2) : pp.129-159.

[16] Ackfeldt, A.L., Coote, L.V. (2005). A Study of Organizational Citizenship Behaviours in a Retail Setting. Journal of Business Research, 58, pp.151-159. 
[17] Bowling, N.A., Wang, Q., Li, H.Y. (2012). The Moderating Effect of Core Self-Evaluations on the Relationships Between Job Attitudes and Organisational Citizenship Behavior. Applied Psychology, 61(1), pp.97-113.

[18] MacKenzie, S.B., Podsakoff, P.M., Ahearne, M., 1998. Some Possible Antecedents and Consequences of In-Role and Extra-Role Salesperson Performance. Journal of Marketing, 62(3).

[19] Homans, G.C. (1958). Social Behavior as Exchange. American Journal of Sociology, Vol. 63, No. 6, pp.597-606.

[20] Emerson, R.M. (1976). "Social Exchange Theory". Annual Review of Sociology 2: pp.335-362.

[21] Organ, D.W., Ryan, K. (1995). A Meta-Analitic Review of Attitudinal and Dispositional Predictors of Organization Citizenship Behavior. Personnel Psychology, Vol. 48, pp.775-802

[22] Hobfoll, S.E. (1989). Conservation of Resources: A New Attempt at Conceptualizing Stress. American Psychologist, Vol. 44, No. 3, pp.513-524.

[23] Uhl-Bien, Mary, Schermerhorn, Jr., John R., Osborn, Richard N. (2014). Organizational Behavior, Experience Grow Contribute (13th ed). 222 Rosewood Drive, Danvers, MA 01923: Clearance Center, Inc

[24] Schermerhorn, Jr. J. R., Osborn, R.N., Uhl-Bien, M., Hunt, J.G. (2012). Organizational Behavior, 12th edition. New Jersey: John Wiley \& Sons.

[25] Robbins, S.P., \& Judge, T.A. (2013). Organizational Behavior, 15th edition. New Jersey: Pearson Education Inc.

[26] George, J.M. \& Jones, G.R. (2012). Understanding and Managing Organizational Behavior, 6th Edition. New Jersey: Prentice Hall.

[27] Wagner III, J.A., Hollenbeck, J.R. (2010). Organization Behavior, Securing Competitive Advantage (revised edition). New York \& Oxon : Routledge.

[28] Chahal, H., Mehta, S. (2010). Antecedents and Consequences of Organizational Citizenship Behavior (OCB): A conceptual Framework in Reference to Health Care Sector. Journal of Services Research, Vol, 10, No. 2, pp.24-44.

[29] Koning, L. F., Van Kleef, Gerben A. (2015). How leaders' emotional displays shape followers' organizational citizenship behavior. The Leadership Quarterly, Vol. 26, pp.489-501.

[30] Foote, D.A., Tang, T.L. (2008). Job satisfaction and Organizational Citizenship Behavior (OCB) Does Team Commitment Make a Difference in Self-directed Teams? Management Decision, Vol. 46 No. 6, pp.933-947.

[31] Intaraprasong, B., Dityen, W., Krugkrunjit, P., Subhadrabandhu T. (2012). Job Satisfaction and Organizational Citizenship Behavior of Personnel at One University Hospital in Thailand. Journal Medical Association Thai. ; Vol. 95 (Suppl. 6), pp.S102-S108.

[32] Mohammad, J., Habib, Farzana Q. Alias, M.A. (2011). Job Satisfaction and Organization Citizenship Behavior: An Empirical Study at Higher Learning Institutions. Asian Academy of Management Journal, Vol. 16, No. 2, pp.149-165.
[33] Pavalache-Iliea, M. (2014). Organizational citizenship behaviour, work satisfaction and employees' personality. Procedia - Social and Behavioral Sciences 127, pp.489- 493.

[34] Swaminathan, S., Jawahar, P.D. (2013). Job Satisfaction as a Predictor of Organizational Citizenship Behavior: An Empirical Study. Global Journal of Business Research, Vol. 7, No. 1, pp.71-80.

[35] Talachi R.K., Gorji M.B., Boerhannoeddin A.B. (2014). The Role of Job Satisfaction in Employees' OCB. Collegium Antropologicum, Vol. 38 No. 2, pp.429-436.

[36] Asiedu, M., Sarfo, J.O., Adjei, D. (2014). Organizational Commitment and Citizenship behavior: Tools to Improve Employee Performance, An Internal Marketing Approach. European Scientific Journal. Vol.10, No.4, pp.288-305.

[37] Azeem, S.M. (2010). Job Satisfaction and Organizational Commitment among Employees in the Sultanate of Oman. Psychology, 2010, 1, pp.295-299. doi:10.4236/psych.2010.14038.

[38] Azeem, S.M. \& Akhtar, N. (2014). The Influence of Work Life Balance and Job Satisfaction on Organizational Commitment of Healthcare Employees. International Journal of Human Resource Studies. Vol. 4, No. 2, pp.18-24.

[39] Bakhshi, A., Sharma, A.D., Kumar, K. (2011). Organizational Commitment as predictor of Organizational Citizenship Behavior. European Journal of Business and Management. Vol 3, No.4.

[40] Devece, C., Palacios-Marqués, D., Alguacil, M.P. (2015). Organizational commitment and its effects on organizational citizenship behavior in a highunemployment environment, Journal of Business Research. http://dx.doi.org/10.1016/j.jbusres.2015.10.069.

[41] Zeinabadi, H. (2010). Job Satisfaction and Organizational Commitment as Antecedents of Organizational Citizenship Behavior (OCB) of Teachers. Procedia Social and Behavioral Sciences. Vol. 5, pp.998-1003.

[42] Liu, Y., Cohen, A. (2010). Values, commitment, and OCB among Chinese employees. International Journal of Intercultural Relations, Vol. 34, pp. 493-506.

[43] Wang, Y. (2015). Examining organizational citizenship behavior of Japanese employees: a multidimensional analysis of the relationship to organizational commitment. The International Journal of Human Resource Management. Vol. 26, No. 4, pp.425-444, http://dx.doi.org/10.1080/09585192.2011.560882.

[44] Noor, A. (2009). Examining Organizational Citizenship Behavior as The Outcome of Organizational Commitment: A Study of Universities Teachers in Pakistan. Proceedings 2nd $C B R C$, Lahore, Pakistan November 14.

[45] Ibrahim, M.A. \& Aslinda, A. (2013). Relationship between Organizational Commitment and Organizational Citizenship Behavior (OCB) At Government-Owned Corporation Companies. Journal of Public Administration and Governance, Vol. 3, No. 3, pp.35-42.

[46] Morin, A.J.S., Vandenberghe, C., Boudrias, J.S., Madore, I., Morizot, J., Tremblay, M. 2011. Affective Commitment and Citizenship Behaviors Across Multiple Foci. Journal of Managerial Psychology. Vol. 26 No. 8, pp.716-738. 
[47] Lavelle, J., Brockner, J., Konovsky, M.A., Price, K.H., Henley, A.B., Taneja, A., Vinekar, W. (2009). Commitment, procedural fairness, and organizational citizenship behavior: a multifoci analysis. Journal of Organizational Behavior. Vol. 30, pp.337-357. DOI: 10.1002/job.518.

[48] Markovits, Y., Davis, A.J., Fay, D., van Dick, R. (2010). The Link Between Job Satisfaction and Organizational Commitment: Differences Between Public and Private Sector Employees, International Public Management Journal, 13:2, pp.177-196, DOI:10.1080/10967491003756682.

[49] Irshad, E., \& Naz, S. (2011). Job Satisfaction, Organizational Commitment and Personality Traits: A relationship Study. Journal of Humanities and Social Science, Vol. XIX, No. 2, pp.37-60.

[50] Gunlu, E., Aksarayli, M., \& Percin, N.S. (2010). Job Satisfaction and Organizational Commitment of Hotel Managers in Turkey. International Journal of Contemporary Hospitality Management, Vol. 22 No. 5, pp.693-717.

[51] Sejjaaka, S.K. \& Kaawaase, T.K. (2014). Professionalism, Rewards, Job Satisfaction and Organizational Commitment amongst Accounting Professionals in Uganda. Journal of Accounting in Emerging Economies, Vol. 4 No. 2, pp.134-157.

[52] Veličković, VM, Višnjić A, Jović S, Radulović O, Šargić Č, Mihajlović J, Mladenović J,. (2014). Organizational Commitment and Job Satisfaction Among Nurses in Serbia: A Factor Analysis, Nursing Outlook, Vol. 62, Issue. 6, pp.415-427. doi: 10.1016/j.outlook.2014.05.003.

[53] Spector, P.E. (1994). Job Satisfaction Survey. Department of Psychology, University of South Florida.

[54] Meyer, J.P. Allen, N.J. (1991). A Three-Component Conceptualization of Organizational Commitment. Human Resource Management Review. Vol.1, No. 1, pp.61-89.

[55] Williams, L.J., Anderson, S.E. (1991). Job Satisfaction and Organizational Commitment as Predictors of Organizational Citizenship and In-Role Behaviors. Journal of Management, Vol. 17, No. 3, pp.601-617.

[56] Hayes, A.F. (2013). Introduction to Mediation, Moderation, and Conditional Process Analysis: A Regression-Based Approach. New York: The Gilford Press. 